\title{
Pregnancy outcome among gestational diabetes mellitus patients in a tertiary care centre
}

\section{Jesu Thangam M., Jameela Ponmalar A. R.*, Vishnupriya S.}

Department of Obstetrics and Gynecology, Sree Mookambika Institute of Medical Sciences, Kulasekharam, Tamil Nadu, India

Received: 08 January 2020

Accepted: 21 January 2020

\section{*Correspondence:}

Dr. Jameela Ponmalar A. R.,

E-mail: jameelaprasanth@gmail.com

Copyright: ( ) the author(s), publisher and licensee Medip Academy. This is an open-access article distributed under the terms of the Creative Commons Attribution Non-Commercial License, which permits unrestricted non-commercial use, distribution, and reproduction in any medium, provided the original work is properly cited.

\section{ABSTRACT}

Background: Gestational diabetes mellitus poses numerous health problems for both mother and the fetus. Even though there are improved outcomes, complications of gestational diabetes still persists. Objectives of this study was to find out the maternal and perinatal outcomes in gestational diabetes mellitus.

Methods: This study was done among pregnant women attending antenatal outpatient department at Sree Mookambika Institute of Medical Sciences, Kulasekharam. oral glucose tolerance test was done at between 24 to 28 weeks and the values more than their cutoff was labelled as gestational diabetes and their outcome was measured as complications during antenatal period, mode of delivery and perinatal outcome in view of neonatal intensive care unit admissions due to hyperbilirubinemia and respiratory distress syndrome.

Results: Out of 500 antenatal mothers 65 were found to have gestational diabetes which is approximately $13 \%$. Obstetric outcomes were $10 \%$ of them developed pregnancy induced hypertension, $12 \%$ of them ended in preterm labour and polyhydramnios in $2 \%$. Delivery by caesarean section and vaginal route is almost similar. Maximum number of neonatal intensive care admissions are due to hyperbilirubinemia followed by respiratory distress.

Conclusions: Screening for gestational diabetes and adequate glycemic control is necessary in preventing short term and long-term complications.

Keywords: Diabetes, Polyhydramnios, Preterm

\section{INTRODUCTION}

Gestational diabetes mellitus is defined as any degree of glucose intolerance with onset or first recognised during pregnancy. The prevalence and incidence of diabetes are increasing globally. In urban India prevalence is $9 \%$ and in rural India prevalence is $4 \%$. Also, diabetes mellitus occurs at younger age in Indian population and this is because of the lifestyle changes with increasing prevalence of obesity, metabolic syndrome and PCOS. ${ }^{1}$

Even though highly improved outcomes were reported over the past few years, complications associated with GDM still persists. There is a higher chance of preeclampsia, preterm delivery and polyhydramnios. And the two important preventable complications are macrosomia and stillbirth as they are related to the degree of maternal glycemic control. This again increase the number of deliveries by caesarean section. Though not all babies have birth defects there is still high probability of congenital defects if the glucose level is not under control during pregnancy and also increased morbidity in terms of hypoglycaemia, hyperbilirubinemia and respiratory distress syndrome warranting NICU admissions. ${ }^{2}$

Objective of this study was to find out the maternal and perinatal outcome in patients with gestational diabetes mellitus 


\section{METHODS}

A prospective observational study was conducted among 500 pregnant women who came for antenatal checkup attending the OPD of department of obstetrics and gynaecology, Sree Mookambika Institute of Medical Sciences during the period from January 2018 to September 2019 was enrolled into the study. All pregnant women with singleton pregnancy were included in the study. A detailed history including maternal age, parity, BMI, and clinical examination along with antenatal checkup was done. Oral glucose tolerance test with 75 grams of glucose were given at 24 to 28 weeks of gestation. Patient was labelled as GDM when any one value more than the following criteria (FBS > $92 \mathrm{mg} / \mathrm{dl}$, one-hour glucose > $180 \mathrm{mg} / \mathrm{dl}, 2$-hour glucose $>153$ $\mathrm{mg} / \mathrm{dl}) .^{3}$ Initially patients were started with diabetic diet, if blood sugar were not controlled on diet insulin was started. Any antenatal complications including urinary tract infection, preeclampsia, polyhydramnios and candidiasis were noted. Both maternal and perinatal outcome in GDM was noted.

\section{Statistical analysis}

Data was entered in Microsoft excel spread sheet 2013 and was analysed by SPSS version 20.0. Descriptive statistics including Mean, Standard deviation and 95\% confidence interval were calculated. Chi-square test was used to find out the associations.

\section{RESULTS}

A prospective observational study was conducted among 500 antenatal mothers attending the OPD of department of obstetrics and gynecology during the period of May 2018 to September 2019. Among the 500 antenatal mothers' majority of them belong to upper lower socioeconomic status (70\%). Mean age of the study participants was 26.69 years with a standard deviation of 4.065 .

Table 1: Maternal complications in GDM.

\begin{tabular}{|lll|}
\hline Maternal complications & Frequency & $\%$ \\
\hline PIH & 7 & 10 \\
\hline Polyhydramnios & 2 & 2 \\
\hline Preterm delivery & 8 & 12 \\
\hline
\end{tabular}

Out of 500 antenatal women tested for OGTT using 75 grams of glucose, about $13 \%$ (65) of antenatal women developed GDM.

Out of 65 GDM mothers, about $10 \%$ ie.,7 antenatal women had pregnancy induced hypertension and only 2 developed polyhydramnios and preterm delivery in $12 \%$ of antenatal women with GDM (Table 1).

Out of 65 GDM patients, about $48 \%$ (32) delivered vaginally which included instrumental deliveries too and the remaining 33 were delivered by lower segment caesarean section (Table 2).

Table 2: Mode of delivery.

\begin{tabular}{|lll|}
\hline Mode of delivery & Frequency & $\%$ \\
\hline Vaginal & 32 & 48 \\
\hline LSCS & 33 & 51.1 \\
\hline
\end{tabular}

Out of 65 babies, $19 \%$ of them had respiratory distress syndrome, $9 \%$ of the babies requiring NICU admissions in view of hypoglycaemia, hyperbilirubinemia and hypocalcemia (Table 3 ).

Table 3: Neonatal complications.

\begin{tabular}{|lll|}
\hline Neonatal complications & Frequency & $\%$ \\
\hline RDS & 13 & 19 \\
\hline Macrosomia & 9 & 14 \\
\hline NICU admissions & 6 & 9 \\
\hline
\end{tabular}

\section{DISCUSSION}

The present study was done among 500 antenatal mothers. The incidence of gestational diabetes mellitus in the present study is estimated to be $13 \%$ which is similar to the study done by Groof et al, where the prevalence of GDM is estimated to be $12.6 \%$ and also the prevalence of GDM is found to be higher in middle and higher socioeconomic class. ${ }^{4}$

Several maternal characteristics were associated with increased risk of developing GDM namely maternal age, pre-pregnancy weight. Similarly, family history of type 2 diabetes was significantly higher in gestational diabetes patients which is in accordance with studies from Reece et al. ${ }^{5}$ Maternal complications like polyhydramnios were found in $2 \%$ of gestational diabetes patients, pregnancy induced hypertension in $7 \%$ of antenatal women, which is similar to the study done by al - Hakeem et al where polyhydramnios were found in $2.2 \%$ women and preeclampsia in $5.3 \% .^{6}$

In the present study there is no significant difference in the mode of delivery which is similar to the study done by Nair et al. ${ }^{7}$

In our study the leading cause for NICU admissions was hyperbilirubinemia followed by respiratory distress which is similar to the study done by Langer et al which shows the leading cause of NICU admissions being hyperbilirubinemia which is about $42 \%$ followed by respiratory complications in babies of GDM mothers which is about $32.3 \% .^{8-10}$

\section{CONCLUSION}

Gestational diabetes mellitus was once thought to be a mild condition but now we know that it carries significant short term and long-term implications for the women and 
their offspring. Screening for diabetes is mandatory in preventing complications as strict glycemic control is necessary for preventing macrosomia and unexplained stillbirths.

\section{Funding: No funding sources}

Conflict of interest: None declared

Ethical approval: The study was approved by the Institutional Ethics Committee

\section{REFERENCES}

1. Seshadri L, Arjun G. Essentials of obstetrics: fourth impression. Haematol Disorders; 2017:740-742.

2. Kumari R, Dalal V, Kachhawa G, Sahoo I, Khadgawat R, Mahey R, et al. Maternal and perinatal outcome in gestational diabetes mellitus in a Tertiary Care Hospital in Delhi. Indian $\mathrm{J}$ Endocr Metab. 2018;22:116-20.

3. Metzger BE. HAPO study cooperative research group. Hyperglycemia and adverse pregnancy outcome (HAPO): Associations with neonatal anthropometrics. Diabet. 2009;58:453-9.

4. Groof Z, Garashi G, Husain H, Owayad S, Albader $\mathrm{S}$, Mouhsen $\mathrm{H}$, et al. Prevalence, risk factors and fetomaternal outcomes of gestational diabetes mellitus in kuwait: a cross sectional study. J Diabet Res. 2019;2019.
5. Reece EA, Leuizamon G, Wiznitzer A. Gestational diabetes: the need for a common ground. The Lancet. 2009;373(9677):1789-97.

6. Al-Hakeem MM. Pregnancy outcome of gestational diabetic mothers: experience in a tertiary care centre. J Fami Comm Med. 2006;13(2):55.

7. Langer O, Rodriguez DA, Xenakis EM, McFarland MB, Berkus MD, Arredondo F. Intensified versus conventional management of gestational diabetes. Am J Obstet Gynaecol. 1994;170(4):1036-47.

8. Nair VG, Sandhu GS, Biswas M, Bhalla R. Evaluation of the incidence and outcome of gestational diabetes mellitus using the current international consensus guidelines for diagnosing hyperglycemia in pregnancy. Int $\mathrm{J}$ Reprod Contracept Obstet Gynecol. 2016;5:336:1-6.

9. Jovanovic-peterson L, Peterson CM. New strategies for the treatment of gestational diabetes. Israel J Med Sci.1991;27(8-9):510-5.

10. Duncan JM. On puerperal diabetes. Trans Obstet Soc Lond. 1882;24:256.

Cite this article as: Thangam JM, Ponmalar JAR, Vishnupriya S. Pregnancy outcome among gestational diabetes mellitus patients in a tertiary care centre. Int J Reprod Contracept Obstet Gynecol 2020;9:942-4. 